\title{
La renta de la tierra en Argentina: los derechos de exportación, período 2003-2014
}

\author{
Ground Rent in Argentina: Export \\ Duties, Period 2003-2014
}

\section{Da renda da terra na Argentina: os direitos de exportação no período 2003-2014}

\author{
Ezequiel Monteforte* \\ Matías Agustín Sánchez **
}

DOI: https://doi.org/10.19053/01203053.v37.n66.2019.7328

Fecha de recepción: 30 de septiembre de 2017

Fecha de aprobación: 6 de marzo de 2018

Cómo citar este artículo/ To reference this article / Comment citer cet article / Para citar este artigo:

Monteforte, E., \& Sánchez, M. (2018). La renta de la tierra en Argentina: los derechos de exportación, período 2003-2014. APUNTES DEL CENES, 37(66). https://doi.org/10.19053/01203053.v37.n66.2019.7328

* Facultad de Ciencias Económicas (FCE), Universidad de Buenos Aires (UBA). Docente de Cuentas Nacionales y de Estructura Social Argentina (FCE-UBA). Buenos Aires, Argentina. ezequielmonteforte@gmail.com. (D) ORCID 0000-0001-8736-4912.

** Licenciado en Economía en la Facultad de Ciencias Económicas (FCE) de la Universidad de Buenos Aires (UBA). Doctorando en Desarrollo Económico en la Universidad Nacional de Quilmes. Docente de Cuentas Nacionales en la Universidad Nacional de General Sarmiento y en la FCE-UBA. Buenos Aires, Argentina. sanchezmatías87@ gmail.com. (1) ORCID: 0000-0001-9790-4839. 


\section{Resumen}

El artículo tiene como objetivo contribuir al estudio de la relevancia de los derechos de exportación en el proceso económico argentino, a través de la discusión sobre los determinantes generales del gravamen y lo ocurrido en el período de la postconvertibilidad. Se recurre a abundante información, a fin de estimar la recaudación del impuesto, complementaria a la información oficial. En particular, la estimación obtenida posee un mayor nivel de desagregación. Además, se propone una clasificación alternativa de las actividades económicas sobre las que efectivamente recae el impuesto y se incorpora el efecto de los reintegros a las exportaciones. Entre los resultados, se sostiene que la relevancia de la recaudación vía este impuesto en el período mencionado se encuentra entre las mayores en términos históricos y fuertemente asociada a la renta de la tierra proveniente de la explotación de los recursos naturales.

Palabras clave: Argentina, cuentas nacionales, derechos de exportación, recaudación impositiva, renta de la tierra, tipo de cambio.

Clasificación JEL: B41, C82, E01, E62, H29 


\begin{abstract}
This article aims to contribute to the research concerning export taxes relevance in the Argentine economic process, based on the analysis on the general determinants of the tax and on the events that occurred during the period after the convertibility. A wide range of information is used in order to estimate tax collection, complementing the official information. In particular, the obtained estimation has a higher level of disaggregation. At the same time an alternative classification of the economic activities over which the tax actually impacts is proposed, and the effect of the refunds over exports is incorporated. Among the results, it is found that the relevance of the tax collection in the aforementioned period is one of the the largest in historical terms and strongly associated with the ground rent due to exploitation of natural resources.
\end{abstract}

Keywords: Argentina, national accounts, export taxes, tax collection, ground rent, exchange rate. 


\section{Resumo}

O artigo procura-se contribuir com o estudo da relevância dos direitos de exportação no processo econômico argentino, começando por discutir os determinantes gerais do imposto e o que aconteceu no período chamado "Pos-Convertibilidad". Para isso, é utilizada uma importante quantidade de fontes de informação para fazer uma estimativa da cobrança do imposto, com o objetivo de complementar a informação oficial. Em particular, a estimativa obtida tem um maior nível de desagregação, enquanto se propõe uma classificação alternativa das atividades econômicas sobre as quais o imposto é cobrado. Além disso, o efeito dos reembolsos das exportações é incorporado. Entre os resultados obtidos encontra-se que a relevância da colheita deste imposto no período mencionado está entre as mais elevadas em termos históricos e fortemente associadas à renda da terra a partir da exploração dos recursos naturais.

Palavras-chave: Argentina, contas nacionais, direitos de exportação, cobrança de impostos, renda da terra, taxa de câmbio. 


\section{INTRODUCCIÓN}

Los derechos de exportación -alternativamente, impuestos o retenciones a las exportaciones - han tenido un papel protagónico en los ingresos fiscales del Estado nacional argentino a lo largo de los últimos quince años. En concreto, luego de la devaluación del peso, que significó el fin de la convertibilidad, en el año 2002, se estableció un esquema de derechos y reintegros a las exportaciones de mercancías, el cual posteriormente fue ampliado y modificado hasta que, a fines de 2015 y principios de 2016, se dejó sin efecto el gravamen para la gran mayoría de los productos alcanzados previamente, con la particular excepción de las mercancías del complejo productivo sojero.

Si bien el impuesto en cuestión estuvo vigente en diversas etapas históricas del proceso de acumulación nacional
(Iñigo, 2007), la relevancia alcanzada por la masa de valor apropiada a través de su recaudación en el producto social anual y en los ingresos fiscales del Estado nacional a lo largo del período 2002-2015 se encuentra entre las de mayor magnitud — solo comparable con lo sucedido en ciertos años de los lapsos 1967-1976 y 1983-1990-. A su vez, como es ampliamente reconocido, esta fuente de riqueza social apropiada por el Estado nacional provino mayormente de las ventas externas de mercancías agrarias (oleaginosas y cereales) y, en segundo plano (aunque novedoso en comparación con el pasado), de aquellas resultantes de la actividad petrolera y minera.

En este marco general, en el presente trabajo nos proponemos dos objetivos principales. En primer lugar, indagar acerca de la fuente de la porción de riqueza social que se obtiene a través 
de los derechos de exportación, aspecto que nos llevará necesariamente a preguntarnos sobre sus vínculos con las condiciones de explotación de los recursos naturales y la renta de la tierra que fluye a través de la circulación de las mercancías resultantes de tales actividades, así como acerca de los límites a la extensión del impuesto, con hincapié en el caso particular de Argentina. En segundo lugar, organizar la información existente, complementándola con la información oficial disponible acerca de la recaudación del impuesto (Anuarios de AFIP, s.f.), con el fin de estimar e identificar con mayor detalle las actividades alcanzadas por el impuesto, así como la relevancia de cada una en la recaudación del mismo. Ello, consideramos, permitirá contar con una base confiable, con un mayor nivel de desagregación que la presentada por AFIP (aunque respetando dicha información oficial), a fin de analizar las actividades productivas desde las cuales fluyó la riqueza social que el Estado captó bajo la forma del impuesto a las exportaciones en el período 2003-2014.

Para ello, luego de presentar en el primer apartado algunas consideraciones de carácter general acerca del proceso de acumulación de capital nacional, con eje en la renta de la tierra que fluye anualmente al país, en el segundo apartado nos centramos en el estudio de sus formas de apropiación primaria y los vínculos con el impuesto a las exportaciones. En el tercer apartado se analiza tanto la relevancia (con una mirada a largo plazo) hacia el interior del proceso económico nacional, como la desagregación según actividades productivas de la recaudación del impuesto a las exportaciones en el período 20032014. Finalmente, sobre la base de los tres apartados previos, se presentan las conclusiones del trabajo'.

\section{BREVE CONSIDERACIÓN EN TORNO AL EJE DEL MOVI- MIENTO GENERAL DE LA ECO- NOMÍA NACIONAL}

El modo de producción capitalista es la primera forma de regir la vida humana con la potencia de organizar la producción en su totalidad, es decir, la esencia del proceso es de contenido mundial, realizándose (como una modalidad concreta del carácter privado que adquiere la organización del trabajo en el modo de producción vigente) bajo la forma de un conjunto de naciones que se interrelacionan como fragmentos del trabajo total de la sociedad (Marx, 2011a). Tanto bajo la división "clásica" como bajo la "nueva división internacional del trabajo" (Fröbel, Heinrichs \& Kreye, 1980) es posible ubicar a Argentina entre un conjunto de países que producen mercancías de origen primario para abastecer al mercado mundial, $\mathrm{y}$, como es ampliamente reconocido en este caso particular, desde la llamada industrialización por sustitución de im-

1 A su vez, a modo de Anexo se introduce un breve recorrido por las principales normativas que entre 2002 y 2016 crearon, eliminaron o modificaron la aplicación del impuesto sobre las distintas mercancías exportadas. 
portaciones (ISI), también mercancías industriales en general para el mercado interno (Diamand, 1972; Iñigo, 2007, 2008; Graña, 2013; Grinberg, 2016).

La relevancia de las actividades primarias en la economía nacional ha sido abordada desde diversos enfoques sobre el proceso de acumulación de capital en Argentina (Prebisch, 1986; Diamand, 1972; Arceo, 2003; Iñigo, 2007; entre otros). En este sentido, consideramos que, dadas las condiciones excepcionales de buena parte de la tierra puesta en producción para la producción de mercancías primarias, el trabajo aplicado a la tierra en Argentina tiene, de manera general, una mayor productividad con relación a las necesarias para abastecer la necesidad social solvente por tales mercancías; por lo que la puesta en producción de dichas tierras abarata el valor de las mercancías en cuestión y, con ello, el valor de la fuerza de trabajo para el capital a escala global, potenciando consecuentemente el proceso global de producción de plusvalía relativa (Iñigo, 1998, 2007).

A su vez, ello implica que, portado en el precio de las mercancías, cuando estas se realizan en el mercado mundial, ingresa al país una porción de plusvalía extraordinaria, por cuanto hay un componente del precio que no tiene como contraparte la producción de valor por parte de los capitales que produjeron las mercancías en cuestión (Marx, 2011b). La misma se fundamenta en plusvalía extraída por los capitales que, vía el valor de la fuerza de trabajo, directa o indirectamente, las compran (Iñigo, 1998, 2007). Por lo tanto, la masa de plusvalía que fluye a un país como Argentina, portada en los precios agrícolas, a la vez que, en primera medida, fue un residuo de potenciar el proceso de producción de plusvalía relativa a escala global, una vez hecho esto, al detraer una porción de plusvalía al proceso de acumulación, resta potencialidad a la acumulación de capital a escala global. Sobre esta base, entendemos que es posible afirmar que, desde el punto de vista de las determinaciones generales del modo de producción capitalista, la potencialidad de la renta de la tierra que ingresa a la Argentina es la de refluir — al menos en alguna porción - a los fragmentos de capital para los cuales originariamente constituyó una detracción de plusvalía ${ }^{2}$. En consecuencia, identificamos este proceso de reapropiación de la renta de la tierra como el eje en torno al cual se desarrolla la acumulación de capital en Argentina $^{3}$ (Iñigo, 2007; Jaccoud et al.,

2 Si bien entendemos que esta determinación general es la que mayormente se realizó en el desarrollo histórico del proceso económico nacional, si se analiza abstractamente, no es esta la única posibilidad.

3 Con esto no pretendemos sostener que dicho contenido general se realiza bajo la misma forma en las distintas etapas históricas de la economía nacional; por el contrario, implica considerar los distintos "modelos de acumulación" que habitualmente se diferencian para dichas etapas. Adicionalmente, es importante resaltar que si bien la renta de la tierra ha ocupado el papel central mencionado en cuanto al movimiento general de la economía nacional, la principal fuente de valorización de los capitales que operan en el país la constituye la extracción de plusvalía a la fuerza de trabajo empleada por los mismos. No obstante, identificamos la renta como fuente especifica de valorización que da unidad al movimiento de la economía nacional en su desarrollo histórico y que permite poner en movimiento diversos aspectos de dicho proceso de acumulación. 
2015; Cazón, Kennedy \& Lastra, 2016; Dileo, Graña, Kennedy \& Sánchez, 2017).

De esta manera, a diferencia de lo ocurrido con los capitalistas, que extraen plusvalía de manera directa a los obreros, el terrateniente no rige su devenir como sujeto social a través de la tasa de ganancia (Marx, 2011b) ${ }^{4}$. Es decir, la cuantía de la renta no está regida por las leyes generales de la acumulación de capital, ya que no se produce como forma concreta de la valorización de un capital individual ${ }^{5}$. Por ello, tal masa de plusvalía puede ser apropiada por otros sujetos sociales, sobre la base de la necesidad mencionada anteriormente, con el límite de la propia reproducción del terrateniente como tal.

Así, de manera alternativa a su apropiación efectiva por el terrateniente, existen mecanismos de apropiación de la renta mediados por la intervención del Estado nacional, en cuanto ejerce (entre otras funciones) la regulación directa de la circulación de la riqueza social hacia el interior de un ámbito nacional (Müller
\& Neusüss, 1975; Alvater, 1976; Iñigo, $2007)^{6}$.

\section{FORMAS DE APROPIACIÓN DE LA RENTA DE LA TIERRA}

La apropiación de la renta de la tierra (en cuanto que plusvalía extraordinaria) por otros sujetos sociales distintos de los terratenientes, puede darse a través de múltiples mecanismos, ya sea antes o después de que llegue al control de estos ${ }^{7}$. Aquí nos interesa resaltar aquellos dos que en el curso concreto del proceso de acumulación nacional han desempeñado el rol más relevante en la apropiación en cuestión y cuyo análisis resulta necesario si nos proponemos abordar la evolución y relevancia de la recaudación vía el impuesto a las exportaciones. El primero, como es evidente, lo constituye el propio impuesto cobrado por el Estado nacional sobre las exportaciones de mercancías de origen primario y otras actividades que operan de manera directa sobre las materias primas. Mientras que el segundo lo constituye la sobrevaluación de la moneda nacional, curso que, de manera indirecta, afecta

$4 \quad$ Cabe aclarar que el terrateniente puede ser propietario de un capital industrial agrario; sin embargo, el análisis de su accionar como sujeto social debe enfocarse desde la "función social" que cada uno representa. El capitalista, la de organizar una porción del trabajo social; el terrateniente, la de apropiar una porción de riqueza social a partir de detentar una porción del planeta. Que estas dos determinaciones como sujeto social, contradictorias entre sí, convivan en una misma persona, no es objetivo de nuestro análisis aquí.

5 Cabe remarcar que la renta brota del devenir de las leyes generales del modo de producción, sin embargo, su cuantía concreta es más bien un residuo del proceso y no la forma específica de moverse.

6 Es por ello que, con el objetivo de profundizar en tales movimientos y en función del espacio disponible, no nos centraremos en la unidad del proceso de acumulación de capital nacional (el cual, claro está, reviste formas mucho más complejas). Por lo tanto, ello implica hacer abstracción (entre otras cosas) de las características de los capitales individuales que actúan hacia el interior del ámbito nacional, sus papeles diferenciados, condiciones productivas y el desarrollo de la conformación histórica de tales aspectos.

7 Entre los primeros se destacan los impuestos sobre las exportaciones agrarias, la sobrevaluación de la moneda nacional, el abaratamiento de las mercancías agrarias en el consumo interno individual y la regulación directa de los precios internos de las mercancías agrarias. Entre los segundos es posible identificar los impuestos directos sobre la renta de la tierra y su colocación en el sistema financiero a tasas de interés reales negativas. Ver Iñigo Carrera (2007). 
la porción de riqueza social plausible de ser apropiada por medio de las retenciones a las exportaciones.

\section{Derechos de exportación sobre las mercancías portadoras de renta y sus derivados}

El cobro de un impuesto sobre el monto total de las exportaciones de mercancías portadoras de renta (es decir, sobre cualquier valor de uso producido bajo condiciones naturales no reproducibles por el trabajo humano, además de los productos agropecuarios, los de origen petrolero, pesquero, minero, etc.) es la forma más simple y directa en que la riqueza social que toma la forma de renta fue y es apropiada. Ahora bien, aunque esta riqueza social está contenida en el monto total de las exportaciones - las cantidades por sus respectivos precios-, es un fenómeno que se expresa únicamente por medio de los precios de las mismas. Esta característica presenta algunos inconvenientes en el momento de aproximarse a su cuantificación.

Si enfocamos el fenómeno en los términos de las Cuentas Nacionales, como puede observarse en la Figura 1, mediante un ejemplo hipotético en moneda nacional de una mercancía portadora de renta, una porción de la riqueza social portada en el precio de mercado de la mercancía en cuestión queda por fuera del cómputo del valor agregado bruto a precios básicos (VABpb), siendo apropiada mediante el impuesto a las exportaciones (que se supone aquí como el único impuesto existente). Bajo estos términos, se crea la apariencia de que el monto de los impuestos a la exportación tiene la misma determinación que cualquier otro, borrando la especificidad de los mismos.

En la misma figura se agrupan los términos que no están directamente determinados por el flujo de renta (la ganancia sobre el capital adelantado de la rama, la masa de salarios y el consumo de capital fijo-CKF-), que, en los dos casos, $\mathrm{t}_{0} \mathrm{y}_{1}$, es de 300 . Ahora bien, luego de descontar esta porción, todo lo que quede de valor en la mercancía constituiría (en condiciones normales) la renta de la tierra. A su vez, se expresa un cambio en los precios de la mercancía portadora de renta de $\$ 600 /$ tonelada a $\$ 1200$, ceteris paribus.

Si se plantea sobre el precio en moneda nacional un impuesto a la exportación del $35 \%$ en los dos casos (para $\mathrm{t}_{0} \$ 600$ x $35 \%=210$; para $\mathrm{t}_{1} \$ 1200$ x $35 \%=$ 420), resultando como diferencia la renta apropiada por el terrateniente ( para $\mathrm{t}_{0}$ $\$ 90$; para $t_{1} \$ 480$ ), como vemos, entre $\mathrm{t}_{0} \mathrm{y} \mathrm{t}_{1}$ la porción de renta que computaría el VABpb pasaría de $\$ 90$ a $\$ 480$, incrementándose también lo recaudado por el impuesto a la exportación de $\$ 210$ a $\$ 420$.

A la vez, es posible notar que el efecto del impuesto produce que la relación entre el VABpb y la renta se invierta, 
es decir, la renta pasa a ser más alta que el VABpb al incrementarse en pesos el precio de la mercancía exportada. El efecto responde a la relación entre la cuantía de la renta y las variables no determinadas directa e inmediatamente por el flujo de renta: la ganancia, la masa salarial y el CKF. De esta forma, desde este enfoque, también es posible sostener que la renta no afecta la reproducción normal de los capitales individuales que producen las mercancías que la portan.

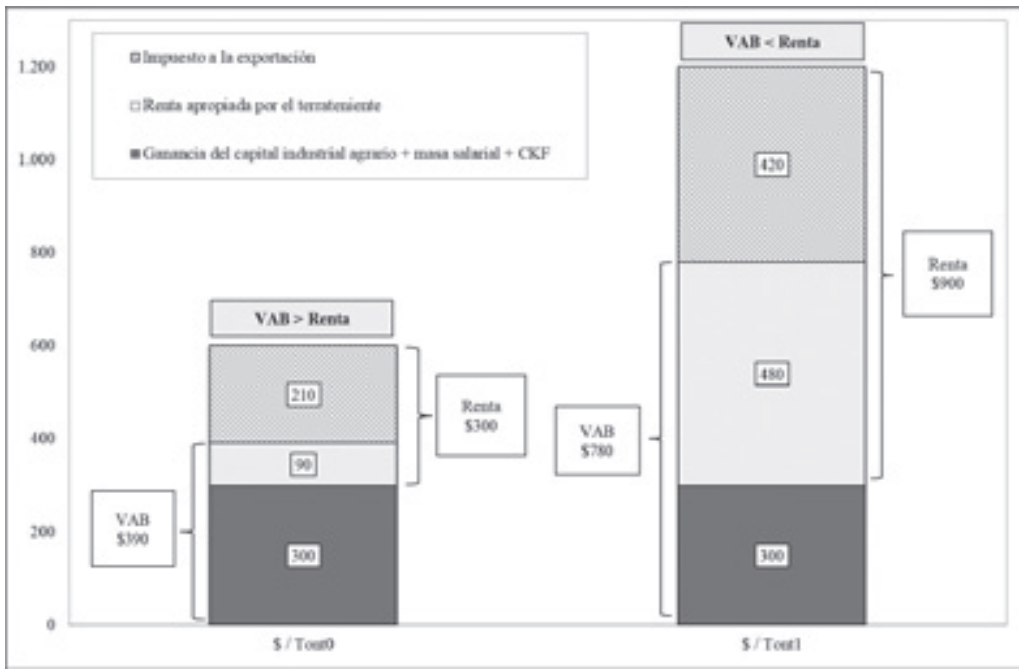

Figura 1. Cambios en las cuantías del VAB a precios básicos y en la renta de la tierra a partir del movimiento unitario del precio de una mercancía hipotética en expresión de moneda nacional en dos momentos temporales hipotéticos (t0 y t1) bajo el efecto del impuesto a la exportación.

Aquí se pone de relieve como, si se pretende cuantificar la plusvalía extraordinaria bajo la forma de renta portada en determinadas producciones, el VABpb no se presenta como un buen indicador del "valor agregado" que tales mercancías encierran cuando la apropiación mediante derechos de exportación juega un rol importante. Cabe marcar una segunda apariencia, atada a la idea de "valor agregado", ya que, aunque existe una parte de este que es un valor genérico producido en nuestro país, la parte de la renta que sí mide el VABpb — los ingresos del terrateniente-, y la que no mide - los derechos a la exportación-, no responden a un valor producido nacionalmente, sino que se presentan como un "falso valor social" que fluye hacia aquí, como indicamos anteriormente (Marx, 2011b; Iñigo, 2007).

Por otra parte, una porción importante de la apropiación de renta mediante los derechos de exportación puede realizarse sobre los capitales individuales que 
procesan las mercancías primarias, toda vez que el impuesto abarata internamente las materias primas $\mathrm{y}$, por ende, una porción de renta queda librada a los compradores en el mercado interno ${ }^{8}$. De allí la posibilidad de implementar el impuesto en la fase posterior del proceso productivo, siempre que la mercancía resultante se comercialice en el exterior, claro está (Iñigo, 2007, pp. 30-31).

En este punto es posible destacar algunos aspectos específicos de la aplicación del impuesto sobre la valorización de los capitales individuales que procesan las materias primas. Considerando el caso hipotético (poroto y aceite de soja) de las tablas 1 y 2 , en el cual se asume como tasa media de ganancia aquella del caso 1 de la Tabla 2 (14,9\%), en primer lugar, es posible notar (ahora enfocado desde el punto de vista de la valorización de los capitales individuales) como la aplicación del impuesto no afecta la normal reproducción de los capitales que producen las materias primas, los cuales obtienen una masa de plusvalía superior a la necesaria para valorizarse a la tasa media de ganancia, conformada por porciones de renta que resultarían apropiadas por los terratenientes.

Tabla 1. Efecto interno de la aplicación de distintas alícuotas del impuesto a las exportaciones sobre la fase I del proceso productivo (capital industrial agrario, producción de granos de soja), para una situación hipotética.

\begin{tabular}{|c|c|c|c|c|}
\hline Caso hipotético & Caso 1 & Caso 2 & Caso 3 & Caso 4 \\
\hline Alícuota del impuesto & $\begin{array}{l}\text { Grano de } \\
\text { soja }(0 \%)\end{array}$ & $\begin{array}{c}\text { Grano de soja } \\
\quad(35 \%)\end{array}$ & $\begin{array}{l}\text { Grano de } \\
\text { soja (30\%) }\end{array}$ & $\begin{array}{l}\text { Grano de } \\
\text { soja }(27 \%)\end{array}$ \\
\hline Precio de mercado (grano) & 750 & 487,5 & 525 & 547,5 \\
\hline Capital constante circulante & 340 & 340 & 340 & 340 \\
\hline $\begin{array}{l}\text { Capital constante fijo } \\
\text { consumido }\end{array}$ & 10 & 10 & 10 & 10 \\
\hline Capital variable & 60 & 60 & 60 & 60 \\
\hline Plusvalía & 340 & 77,5 & 115 & 137,5 \\
\hline Tasa de ganancia (1) & $82,9 \%$ & $18,9 \%$ & $28,0 \%$ & $33,5 \%$ \\
\hline $\begin{array}{l}\text { Renta apropiada vía el } \\
\text { impuesto }\end{array}$ & - & 262,5 & 225 & 202,5 \\
\hline
\end{tabular}

Nota: (1) incluye porciones de renta.

8 Desde un enfoque diferente, el efecto del impuesto sobre el precio interno de las materias primas puede encontrarse desarrollado en Piermartini (2004). 
Ahora bien, en la segunda fase del proceso productivo planteado como ejemplo, dependiendo de las alícuotas relativas entre las fases productivas y la composición del precio de costo de cada capital individual en su proceso productivo, la alícuota sobre las fases posteriores podría llegar a afectar la ganancia normal de los capitales o, inversamente, permitirles apropiar porciones de renta. Esto último tendrá lugar, por ejemplo, en una situación de incremento en los precios (relativos) internacionales de las materias primas, manteniéndose fijas las alícuotas en las distintas fases, ya que el insumo portador de renta tendrá creciente peso en el precio de costo.

Sobre la base de los posibles casos mencionados se presenta la Tabla 2. Allí es posible observar que incluso en aquella situación en la cual la tasa de ganancia es superior a la media (caso 4 de la Tabla 2), el total apropiado vía el impuesto supera la masa de renta portada en la materia prima utilizada en el proceso productivo. Sumado a ello, si bien en los casos en los que la tasa de ganancia resulta menor a la media (casos 2 y 3 de la Tabla 2) podría pensarse que la diferencia entre el total recaudado mediante el impuesto y la renta portada en la materia prima utilizada corresponde a la plusvalía necesaria para alcanzar dicha tasa, también en estas situaciones se observa que tal diferencia es mayor a la porción de plusvalía necesaria para alcanzar la situación normal.

A fin de centrar el análisis en la diferencia entre el total recaudado y la renta portada en las materias primas procesadas, consideremos el caso 5 de la Tabla 2 , en el cual se supone un esquema del impuesto tal que el capital individual de la fase II del proceso productivo realiza una ganancia normal (de acuerdo con nuestro ejemplo hipotético). Allí puede verse (comparado con el caso 2, ya que se corresponde con un impuesto idéntico sobre la materia prima) que efectivamente mediante el impuesto aplicado sobre esta fase del proceso productivo, el Estado podría apropiar una mayor masa de plusvalía que aquella correspondiente a la renta portada en el precio de las materias primas utilizadas en el proceso productivo. El aspecto específico que surge al aplicarse el impuesto sobre esta fase del proceso productivo es el abaratamiento del capital circulante adelantado, producto de la existencia del impuesto en la fase I de la producción, y la correspondiente porción de plusvalía que queda liberada desde el punto de vista de la necesidad de valorización normal del capital de la fase II $^{9}$. Esta masa de plusvalía, creada en el ciclo productivo del capital individual que procesa la materia prima,

$9 \quad$ Más específicamente, producto de la existencia de plusvalía extraordinaria bajo la forma de renta materializada en los precios comerciales del insumo y la existencia de un impuesto sobre la exportación del mismo, no sólo se abarata internamente la materia prima para el capital que la procesa, sino que también queda liberada -desde el punto de vista de la necesidad de valorización de este capital- una porción de plusvalía que, de regir una situación sin impuesto a la exportación de la materia prima en cuestión -es decir, el precio internacional-, hubiera sido necesaria para la realización de la ganancia normal, pero que dado el abaratamiento del insumo deja de tener tal necesidad. 
puede ser apropiada mediante la aplicación del impuesto a la exportación sobre esta fase del proceso de producción sin afectar la normal valorización del capital individual, aunque no sería esta la única posibilidad. De hecho, como se observa en el caso 6 de la misma tabla, si la alícuota del impuesto sobre la segunda fase del proceso productivo es igual a aquella que permite apropiar una masa de plusvalía equivalente a la renta hipotética que hubiera sido apropiada de cobrarse el impuesto sobre la materia prima el capital que las procesa obtiene una ganancia extraordinaria.

Este aspecto específico de la aplicación del impuesto, que se origina en la existencia de renta de la tierra portada en los precios de la materia prima, se constituye en la segunda fuente posible (aquí identificada) de los derechos de exportación recaudados por parte del Estado nacional.

Tabla 2. Efecto interno de la aplicación de distintas alícuotas del impuesto a las exportaciones sobre la fase II del proceso productivo (capital industrial, producción de aceite de soja), para una situación hipotética.

\begin{tabular}{|c|c|c|c|c|c|c|}
\hline Caso hipotético & Caso 1 & Caso 2 & Caso 3 & Caso 4 & Caso 5 & Caso 6 \\
\hline \multirow{2}{*}{ Alícuota del impuesto } & $\begin{array}{c}\text { Grano } \\
\text { de soja } \\
(0 \%)\end{array}$ & $\begin{array}{c}\text { Grano } \\
\text { de soja } \\
(35 \%)\end{array}$ & $\begin{array}{c}\text { Grano } \\
\text { de soja } \\
(30 \%)\end{array}$ & $\begin{array}{l}\text { Grano } \\
\text { de soja } \\
(30 \%)\end{array}$ & $\begin{array}{l}\text { Grano } \\
\text { de soja } \\
(35 \%)\end{array}$ & $\begin{array}{c}\text { Grano } \\
\text { de soja } \\
(35 \%)\end{array}$ \\
\hline & $\begin{array}{l}\text { Aceite } \\
\text { de soja } \\
(0 \%)\end{array}$ & $\begin{array}{l}\text { Aceite } \\
\text { de soja } \\
(32 \%)\end{array}$ & $\begin{array}{l}\text { Aceite } \\
\text { de soja } \\
(27 \%)\end{array}$ & $\begin{array}{l}\text { Aceite } \\
\text { de soja } \\
(24 \%)\end{array}$ & $\begin{array}{l}\text { Aceite } \\
\text { de soja } \\
(30,17 \%)\end{array}$ & $\begin{array}{c}\text { Aceite } \\
\text { de soja } \\
(26,25 \%)\end{array}$ \\
\hline $\begin{array}{l}\text { Precio de mercado } \\
\text { (Aceite de soja) }\end{array}$ & 1.000 & 680 & 730 & 760 & 698,3 & 737,5 \\
\hline $\begin{array}{l}\text { Capital constante } \\
\text { circulante (grano) }\end{array}$ & 750 & 487,5 & 525 & 525 & 487,5 & 487,5 \\
\hline $\begin{array}{l}\text { Capital constante } \\
\text { fijo consumido }\end{array}$ & 10 & 10 & 10 & 10 & 10 & 10 \\
\hline Capital variable & 110 & 110 & 110 & 110 & 110 & 110 \\
\hline Plusvalía & 130 & 72,5 & 85 & 115 & 90,8 & 130 \\
\hline Tasa de ganancia (1) & $14,9 \%$ & $11,9 \%$ & $13,2 \%$ & $17,8 \%$ & $14,9 \%$ & $21,4 \%$ \\
\hline $\begin{array}{l}\text { Total apropiado } \\
\text { vía impuesto a la } \\
\text { exportación (2) }\end{array}$ & - & 320 & 270 & 240 & 301,7 & 262,5 \\
\hline
\end{tabular}


Continuación Tabla 2.

\begin{tabular}{|c|c|c|c|c|c|c|}
\hline $\begin{array}{l}\text { Renta hipotética } \\
\text { que hubiera sido } \\
\text { apropiada vía el } \\
\text { impuesto sobre la } \\
\text { materia prima (sin } \\
\text { procesamiento) }\end{array}$ & - & 262,5 & 225 & 225 & 262,5 & 262,5 \\
\hline Diferencia & - & 57,5 & 45 & 15 & 39,2 & - \\
\hline \multicolumn{7}{|c|}{ Desagregación del total recaudado $=A+B+C-D$} \\
\hline $\begin{array}{l}\text { A: Renta apropiada } \\
\text { mediante el impuesto }\end{array}$ & - & 262,5 & 225,0 & 225,0 & 262,5 & 262,5 \\
\hline $\begin{array}{l}\text { B: Plusvalía liberada } \\
\text { por el efecto del } \\
\text { impuesto sobre el } \\
\text { insumo }\end{array}$ & - & 39,2 & 33,6 & 33,6 & 39,2 & 39,2 \\
\hline $\begin{array}{l}\text { C: Plusvalía normal } \\
\text { apropiada a los } \\
\text { capitales individuales }\end{array}$ & - & 18,3 & 11,4 & - & - & - \\
\hline $\begin{array}{l}\text { D: Plusvalía liberada } \\
\text { apropiada por los } \\
\text { capitales individuales }\end{array}$ & - & - & - & 18,6 & - & 39,2 \\
\hline
\end{tabular}

Notas: (1) la tasa de ganancia del caso 1 se asume como la media, tomando que el capital constante fijo adelantado se agota en un período. (2) En los casos en los que la tasa de ganancia es menor a la media, incluye plusvalía normal apropiada a los capitales en cuestión.

De esta manera, consideramos que la fuente de los impuestos a las exportaciones la constituye, de manera general, la renta de la tierra (y, de acuerdo con el esquema del impuesto, las porciones de plusvalía plausibles de ser liberadas que hemos identificado), en cuanto no afectan la normal reproducción de los capitales que producen las mercancías que la portan (ni la de aquellos capitales que las procesan, cuando estos acceden a las mismas de manera abaratada). De hecho, tal como veremos más adelante, prácticamente la totalidad de la recaudación del impuesto en el período
2003-2014 se origina en las actividades productoras de materias primas y sus subproductos. No obstante, ello no quita que existan capitales que - a un determinado precio de mercado- podrían valorizarse, pero debido al recorte en el precio que implica la vigencia del impuesto, los mismos no pueden hacerlo (Iñigo, 2007, pp. 18-19), al menos en condiciones normales.

Este aspecto de las retenciones a las exportaciones se ve reforzado en etapas específicas del proceso de acumulación 
nacional ${ }^{10}$, particularmente si tienen lugar a la par de procesos de sobrevaluación de la moneda. Ello se debe a que si bien con la sobrevaluación la porción de riqueza social apropiada mediante el impuesto se ve menguada, el total resulta incrementado. En este punto es necesario analizar el segundo de los mecanismos de apropiación mencionados.

\section{La sobrevaluación de la moneda na- cional para las exportaciones de ma- terias primas y derivados}

Considerando el precio de las mercancías como la expresión de valor que ellas encierran, siendo este, a su vez, materialización de la cantidad de trabajo abstracto socialmente necesario desplegado de manera privada e independiente, podemos pensar que la relación de cambio entre dos signos de valor o monedas de curso legal es la forma nacional y extranacional concreta en la que dichos precios se expresan. En este sentido, si pensamos en la posibilidad de que la relación de cambio entre dos monedas, o "tipo de cambio", se encuentre fuera de la paridad, nos enfrentamos a que las mercancías o flujos dinerarios que queden expuestos a esta relación de cambio, por sobre o por debajo de la paridad, recibirán o perderán porciones de valor que le pertenecían en la expresión monetaria previa a la conversión (Iñigo, 2007; Kennedy, 2015, 2016).
Debido al carácter generalizado que hoy presenta la teoría marginalista, con la concerniente incapacidad para enfrentar al precio como expresión del valor, la sobrevaluación y la subvaluación cambiaria se presentan como formas enmascaradas ideológicamente de refluir riqueza social. Aunque este proceso se manifiesta de manera general, en los países que producen mercancías con productividades del trabajo diferenciales con base en condicionamientos naturales específicos (Argentina con las materias primas agropecuarias y en menor medida las mineras, como el petróleo, por ejemplo; Chile y Perú con las materias primas mineras, el cobre por ejemplo; Venezuela con el petróleo; Australia con materias primas agropecuarias y mineras; entre otros) se presenta con una forma por demás particular, tendiendo el tipo de cambio a moverse por sobre la paridad (Grinberg, 2013). En estos términos, por ejemplo, el peso argentino con respecto al dólar se encuentra sobrevaluado cuando se necesita un "esfuerzo mayor" de parte del dólar para comprar una determinada cantidad de pesos en relación con los que correspondería si el tipo de cambio estuviese a la par. La otra cara de la moneda de la sobrevaluación es un particular poder de compra del peso argentino con respecto al dólar, donde cada peso vale más dólares de lo que debería si el tipo de cambio estuviese a la par. Así, por ejemplo, en etapas en las cuales domina la sobrevaluación cambiaria, es fácil no-

\footnotetext{
10 De hecho, en el desarrollo concreto, tarde o temprano los impuestos a las exportaciones ponen abiertamente de manifiesto el carácter antagónico de la apropiación en cuestión, tanto que a partir de un momento determinado pasan a considerarse "confiscatorios".
} 
tar un abaratamiento de las mercancías externas o importadas en detrimento de las de producción nacional, una creciente fuga de capitales para aprovechar el poder adquisitivo acrecentado del peso para comprar una moneda externa y un creciente giro de utilidades al exterior, dado que la tasa de ganancia interna se multiplica al comprar dólares con un peso por sobre la paridad (Dileo et al., 2017).

A su vez, al convertirse a pesos las divisas provenientes de las exportaciones, el nivel de sobrevaluación incidirá negativamente en la multiplicación de dichas divisas en la mediación cambiaria, de manera inversa a lo señalado para el caso de la fuga de capitales y la remisión de utilidades y dividendos. Es por ello que la incidencia en el ámbito nacional del impuesto a las exportaciones también se verá necesariamente afectada a medida que la moneda se mueve de su nivel de paridad, y, con ello, la apropiación de renta por dicha vía.

En otras palabras, si el tipo de cambio se encuentra sobrevaluado, parte del valor íntegro de la mercancía que debería cobrar el exportador queda atrapado en la mediación cambiaria. Por ello, la existencia de los impuestos a la exportación conjuntamente con el efecto (creciente) de la sobrevaluación, si bien no afecta la cuantía total de renta, sí cambia su forma de apropiación. En estos términos, tanto el terrateniente como el Estado nacional ven escapárseles porciones de riqueza social a manos de la sobrevaluación cambiaria, ya que una vez realizadas las mercancías en el mercado mundial, la mediación cambiaria reduce su expresión en moneda nacional en términos relativos $\mathrm{y}$, por ende, enfocado desde el punto de vista de los derechos de exportación, la base imponible. Es decir, dado que el tipo de cambio se encuentra sobrevaluado y los bienes sujetos al impuesto pasan por su mediación, al pagarse el tributo, este pierde terreno frente a la evolución de los precios internos ${ }^{11}$.

Volviendo sobre el ejemplo hipotético planteado anteriormente (Figura 1), veamos ahora el efecto del impuesto a la exportación cuando se suma el efecto de la sobrevaluación cambiaria en el valor íntegro de las mercancías portadoras de renta (Figura 2).

11 Si ocurriera la situación inversa, esto es, una subvaluación de la moneda nacional, a todo lo dicho anteriormente le cabría el caso inverso, por tanto ganando relevancia el impuesto a las exportaciones luego de realizarse la mediación cambiaria. 


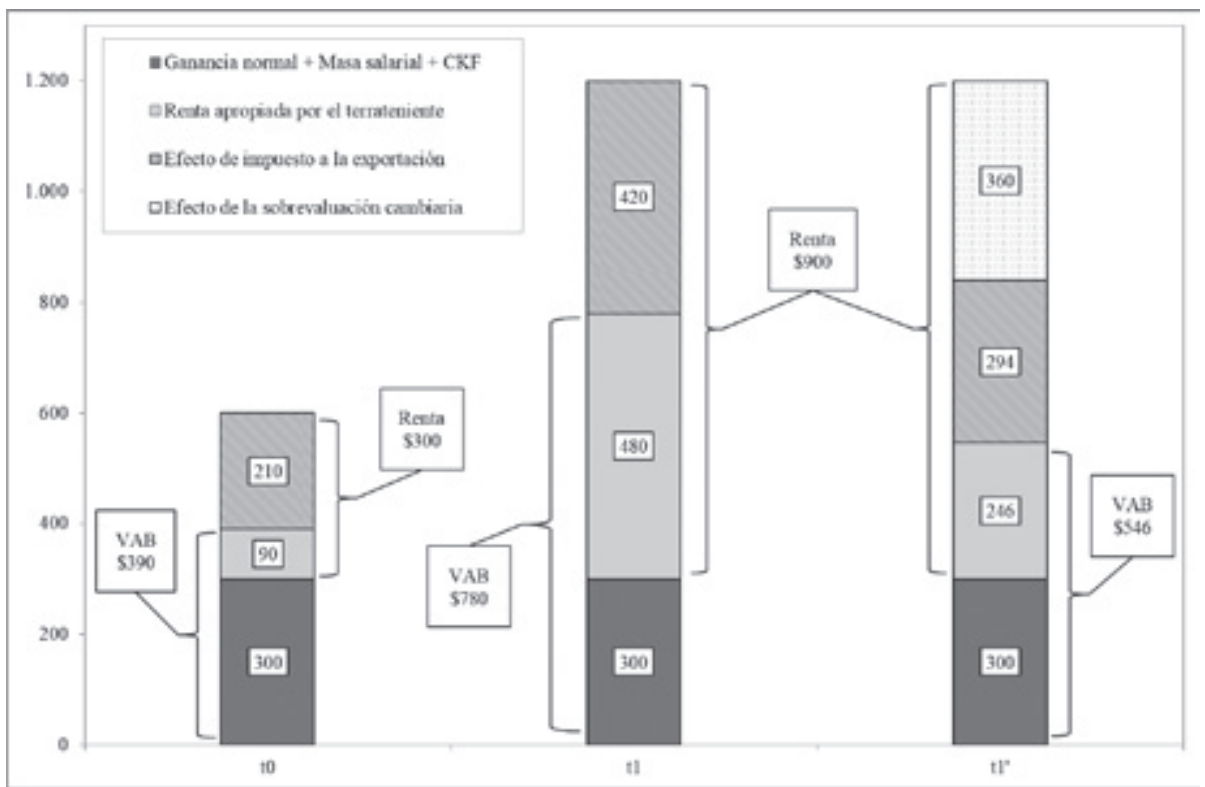

Figura 2. Cambios en las cuantías del VAB a precios básicos y en la renta de la tierra a partir del movimiento unitario del precio de una mercancía hipotética, en expresión de moneda nacional, en dos momentos temporales hipotéticos bajo el efecto del impuesto a la exportación (t0 y t1) y sumando el efecto de la sobrevaluación cambiaria (t1')

En la Figura 2 se muestra el efecto de los impuestos a la exportación, tal como lo vimos en el subapartado anterior, sumando el efecto de una sobrevaluación cambiaria de un $30 \%$ en un hipotético momento t1'. Como vemos, la cuantía total de la renta no cambia entre tl y tl', sino que solo cambia la forma de apropiación de la misma. De esta manera, tanto el terrateniente como el Estado nacional pierden porciones de riqueza social como consecuencia de la sobrevaluación cambiaria. Si el tipo de cambio estuviese a la par y solo rigieran las retenciones como forma de apropiación de renta, el terrateniente se embolsaría $\$ 480$ y el Estado nacional $\$ 420$ por cada tonelada de mercancía exportada.
Ahora bien, con la sobrevaluación como mecanismo de apropiación de renta, el terrateniente se apropia \$246 y el Estado nacional, \$294, quedando en la mediación cambiaria $\$ 360$.

Así mismo, la sobrevaluación cambiaria es una forma específica de absorber por parte del resto de la sociedad una mayor parte de la plusvalía extraordinaria que conforma la renta que, de otra manera, quedaría en manos de los terratenientes. A su vez, este efecto reduce aún más la expresión de VABpb con relación a la renta total. Así, tanto los impuestos a la exportación como el efecto de la sobrevaluación cambiaria comprimen la estimación del "valor agregado", mientras 
que la propia sobrevaluación comprime la relevancia del impuesto ${ }^{12}$.

Nuevamente, para que un capital pueda valorizarse de manera normal teniendo que pasar constantemente por una mediación cambiaria sobrevaluada, el precio de la mercancía que vende en el mercado mundial debe encerrar una parte que no haga a su precio de producción, esto es, en nuestro caso, una parte del precio comercial es renta de la tierra. En el caso contrario, es decir, aquel de un capital cuya mercancía no porta una parte de renta en su precio comercial, se vería impedido de reproducirse en tales condiciones, ya que constantemente debería vender su mercancía por debajo de dicho precio $\mathrm{y}$, por ende, se vería imposibilitado de realizar una ganancia normal. Por otra parte, un capital que se beneficie por importar sus medios de producción continuamente a un menor precio de producción en relación con el precio internacional, necesariamente debe obtener esa ganancia extraordinaria de una fuente distinta a su normal reproducción.

\section{METODOLOGÍA}

El procedimiento de cálculo de los derechos y reintegros a las exportaciones desagregado según actividades productivas, para el período 2003-2014, siguió los lineamientos metodológicos que se enumeran a continuación, a partir de considerar un amplio conjunto de fuentes de información. En primer lugar, se tuvieron en cuenta las exportaciones anuales en dólares FOB desagregadas a 12 dígitos de la Nomenclatura Común del Mercosur (NCM). Sobre tales valores (agrupados a 8 dígitos de

12 Si bien no es el punto central que aquí pretendemos mostrar, corresponde aclarar la forma en que se completa este movimiento. En este sentido, hasta aquí mencionamos que la mediación cambiaria es una forma de apropiación de renta, pero ¿cómo se realiza tal redistribución? Pues bien, a través de todos aquellos sujetos que tengan acceso a la compra de los dólares abaratados. En términos más generales, todo aquel que logre realizar la mediación cambiaria en el sentido contrario a la del exportador está subsidiando sus compras por medio de la renta que se materializó en cada dólar sobrevaluado. No es casual entonces que en tales etapas la demanda de divisas se incremente fuertemente. Por ejemplo, supongamos que una empresa compra una maquinaria importada, la cual vvale 5.000 dólares. Con un tipo de cambio de paridad de 30 pesos por dólar, la empresa debería desembolsar 150.000 pesos para adquirirla. Ahora bien, se encuentra que el tipo de cambio en realidad es de 15 pesos por dólar, por lo que solo con 75.000 pesos la puede comprar. ¿De dónde brotan los 75.000 pesos faltantes? Pues la porción de riqueza que queda en la mediación cambiaria en la venta de las mercancías portadoras de renta está contenida en los dólares que el Banco Central vende, también sobrevaluado, a los importadores. Y, entonces, ¿en dónde aparece esa porción de riqueza social respecto a la estimación de VABpb? Pues bien, ese medio de producción abaratado entra en el proceso productivo del capital individual que la adquirió, apareciendo, en principio, un monto de valor que debería corresponder a la reposición del capital constante desgastado en la producción de la mercancía como ganancia. Los capitales que compran medios de producción abaratados por la sobrevaluación cambiaria obtienen una ganancia extraordinaria en sus balances como contrapartida, apareciendo porciones de renta en todos y cada uno de los VABpb de las ramas de producción que importan medios de producción a un tipo de cambio sobrevaluado. Por ende, parte de la renta se encuentra diluida en el VABpb del resto de las ramas de producción. Obviamente, lo mismo aplica para las importaciones de insumos, utilizados como capital constante circulante en los procesos productivos. Algo parecido sucede con el giro de utilidades de filiales extranjeras. Supongamos que una empresa desea girar utilidades por 3.000 pesos. Con un tipo de cambio de paridad de 30 pesos por dólar, la empresa podría comprar 100 dólares y esa sería la utilidad que giraría a su casa matriz. Ahora bien, con la sobrevaluación cambiaria, la empresa encuentra que el tipo de cambio no es de 30 , sino de 15 pesos por dólar, con lo que puede comprar 200 dólares. ¿De dónde salieron esos 100 dólares? Otra vez, de la riqueza en forma de renta que queda contenida de manera indirecta en los dólares sobrevaluados. Existen varios efectos más por donde se debe seguir el fluir de la renta entre las manos de los distintos actores sociales, algunos de los cuales han sido mencionados en el texto, como la baratura relativa de la fuerza de trabajo con la que se encuentra el capital que se acumula a escala nacional por circular las mercancías agrarias a un precio menor al internacional. 
la NCM), se aplicaron las alícuotas de la NCM respectivas de cada posición arancelaria para cada año del período, tanto de derechos como de reintegros a las exportaciones, también agrupadas a 8 dígitos, para su compatibilización con la base de datos de comercio exterior. A su vez, se utilizó una clasificación de actividades productivas a partir de las características materiales de cada producto de las posiciones de la NCM para el agrupamiento correspondiente.

No obstante, previo a la aplicación de las alícuotas de la NCM vigentes en cada año, se aplicaron dos coeficientes de ajuste sobre el valor FOB de las exportaciones para obtener una aproximación a la base imponible del impuesto, sobre la cual se aplican las alícuotas ${ }^{13}$. El primero de dichos ajustes consiste en descontar del valor FOB la alícuota del derecho de exportación de cada posición arancelaria, mientras que el segundo consiste en excluir del cálculo de la base imponible el componente importado para la producción de la mercancía exportada. Un caso particular se da en aquellos productos agropecuarios con FOB oficial y los combustibles, para los cuales la aplicación de la alícuota es en forma directa.

De esa manera, sobre la estructura de recaudación por actividades productivas obtenida de las bases previas, se tomó como referencia la recaudación en concepto de derechos de exportación desagregada por secciones de la NCM publicada por el organismo recaudador nacional (AFIP). De tal forma, se compatibilizó la estructura obtenida en la estimación (desde el nivel de 8 dígitos hasta las secciones de la NCM) con el dato oficial al nivel de secciones de la NCM, con el objetivo de respetar la información oficial disponible para cada año. En el caso de los reintegros a las exportaciones, al no contar con información oficial disponible, se trabajó con los resultados obtenidos en la estimación propia, convertidos a pesos por el tipo de cambio nominal promedio anual.

A su vez, corresponde señalar algunos aspectos de la metodología que podrían implicar sesgos en la estimación (es decir, al nivel de desagregación menor a las secciones de la NCM). En primer lugar, el cálculo de los derechos y reintegros se realizó con un nivel de desagregación de 8 dígitos de la NCM, a partir de un promedio simple de las alícuotas a 12 dígitos; lo cual podría implicar algún sesgo dependiendo del total exportado por cada posición a 12 dígitos, en aquellos casos en los que hacia el interior de los agrupamientos a 8 dígitos difieren las alícuotas. Segundo, para el armado de la tabla con las alícuotas de derechos y reintegros se tomó el último dato disponible para cada año para cada posición arancelaria; no obstante, para los años 2005, 2006 y 2008, no se contó con los datos de la NCM, por lo que

13 Estos coeficientes determinan el monto en pesos sobre el cual la Aduana aplicará la alícuota para hacer efectivo el pago del impuesto. 
en tales casos se tomaron los registros del año anterior. En tercer lugar, para los productos agrícolas con valor FOB oficial, el organismo encargado de la aplicación del impuesto lo hace sobre tal valor, independientemente del precio al que se exporte la mercancía. Es por ello que al tomar en la estimación como referencia el valor FOB de las exportaciones anuales y aplicar las alícuotas sobre dicho total, pueden existir diferencias respecto del valor FOB oficial. En el caso de los productos de origen petrolero, para aquellas posiciones que en el período considerado han tenido retenciones móviles, este mecanismo no ha sido captado por el cálculo ${ }^{14}$. En cuarto lugar, para la conversión a pesos de los resultados obtenidos en dólares para los reintegros a las exportaciones (no así para los derechos de exportación, ya que se parte de la información de recaudación oficial) se utilizó el tipo de cambio nominal promedio anual, por lo que podrían surgir sesgos en función de la fecha de realización de las exportaciones, especialmente para aquellas actividades con marcada estacionalidad en la comercialización. Por último, como dijimos, para consolidar los resultados obtenidos, estos se agruparon al nivel de secciones de la NCM y se ajustaron a los datos de recaudación de AFIP al mismo nivel de apertura de la información. El ajuste en cuestión se realizó de manera proporcional para todas las posiciones arancelarias a 8 dígitos que conforman cada sección, dado que a priori no nos resultó posible identificar las posiciones en las que podrían estar portadas en mayor medida las diferencias.

Por otra parte, cabe aclarar que la forma de estimar los impuestos a las exportaciones aquí propuesta difiere de la estimación realizada por las Cuentas $\mathrm{Na}$ cionales Argentinas para la base 2004, en las cuales los derechos de exportación para el año base se obtienen con base en los productos (de acuerdo con la Clasificación Central de Productos), pero que surgen de aplicar coeficientes (determinados por la participación de cada producto en las exportaciones por capítulo de la $\mathrm{NCM}$ ) a la recaudación de los derechos de exportación según capítulos de la NCM (Instituto Nacional de Estadística y Censos [INDEC], 2016), obteniendo de manera implícita la alícuota para cada producto. En el presente trabajo, en cambio, partimos de respetar la alícuota de cada posición de la NCM (la cual no necesariamente se corresponde de manera directa con el flujo relativo de exportaciones anuales), para luego aplicar la participación resultante a la recaudación a nivel de secciones de la NCM publicada por AFIP. De manera adicional, en el momento de escribir este trabajo, los datos de la estimación oficial solo se encuentran presentados de manera desagregada para el año 2004 en el COU, aunque de manera conjunta con otros impuestos a los productos netos de subsidios, lo cual no permite analizar de manera separa-

14 Por ello consideramos que en este sector particular (más allá de la consolidación con los datos de AFIP al nivel de secciones de la NCM), podrían presentarse mayores sesgos relativos en los resultados obtenidos al nivel más desagregado. 
da la relevancia de los derechos a las exportaciones ${ }^{15}$.

En ese sentido, la clasificación de actividades aquí utilizada permite agrupar las posiciones de la NCM en función de sectores productivos, los cuales se cruzaron con las secciones de la $\mathrm{NCM}^{16}$. Sobre dicha base, la reclasificación propia utilizada en el siguiente apartado parte, en primer lugar, de aproximarse a los sectores de actividad usualmente empleados en las cuentas nacionales, para luego identificar, de acuerdo con lo desarrollado en el apartado previo, las actividades en las que se originan las porciones de riqueza social apropiadas por el Estado nacional mediante los impuestos a las exportaciones. Por lo tanto, es importante dejar en claro que al reconocer que la riqueza social en cuestión es originada en las actividades productivas que explotan recursos naturales, los derechos de exportación (en cuanto mecanismo de apropiación de la renta de la tierra) cobrados sobre las actividades que procesan materias primas deben ser considerados como parte del "valor agregado" de aquellas (siempre que se consideren los impuestos indirectos en el mismo), a diferencia de lo realizado por las cuentas nacionales. Por lo tanto, el agrupamiento planteado hace referencia a una porción de riqueza social originada en los sectores que explotan recursos naturales que escapa a dicho cómputo. Obviamente, la estimación propuesta es una aproximación al fenómeno, ya que el mismo podría estar mediado por otros flujos de riqueza social, tal como vimos en el apartado previo.

\section{RESULTADOS}

\section{Peso en el PBIpm y en la recaudación del Estado nacional}

Previo a observar con mayor detalle lo ocurrido en el período 2003-2014, en primer término, vale poner en perspectiva histórica la relevancia que ha tenido el impuesto a la exportación en el país. Como queda claro en la Figura 3, ello varía marcadamente para distintas etapas. En particular, se destacan los períodos 1967-1977, 1982-1991 y 20022016, aunque es en esta última etapa (especialmente entre 2002 y 2012) cuando es posible identificar una relevancia sostenida del impuesto en la recaudación nacional (entre el $8 \%$ y el $12 \%$ ), a diferencia de las fluctuaciones de los restantes períodos resaltados. A su vez, en dicha etapa el impuesto en cuestión alcanza la mayor magnitud con relación al PBIpm, llegando al 3,1 \% en 2008. No obstante, a partir de 2010 la relevancia del impuesto cae sostenidamente (a excepción de 2010 y 2014). Esto se debe, entendemos, a dos cuestiones previamente mencionadas. Por un lado, a la

\footnotetext{
15 En relación con lo dicho anteriormente, la estimación aquí presentada no pretende ser superadora ni plantearse como alternativa a la realizada por las cuentas nacionales de manera oficial, sino que el objetivo es presentar una estimación complementaria, aunque con diferencias en cuanto a los procedimientos del cálculo y formas de presentación de la información.

16 La información desagregada no se presenta aquí en función del espacio disponible. La misma puede ser solicitada a los autores a través de los correos electrónicos indicados oportunamente.
} 
creciente sobrevaluación de la moneda. Por otro, si bien hacia fines de 2015 la devaluación del peso fue mayor a la de 2014, esta se dio en paralelo a la eliminación de los derechos de exportación para la mayor parte de las mercancías, con la particular excepción del complejo sojero, además de que la liquidación de divisas se extendió en el tiempo.

Justamente, para resaltar dicho movimiento, en la misma Figura 3 se incluyen dos series adicionales a modo de indicadores: la evolución del tipo de cambio real de la moneda nacional en relación con el dólar estadounidense y el índice (en términos reales) de precios internacionales de granos ${ }^{17}$. De manera general, es posible identificar que, para los tres períodos identificados previamente, el tipo de cambio y los precios internacionales tuvieron importancia diferenciada. Así, en el primero de ellos se destaca un elevado nivel de precios internacionales, mientras que en los años ochenta se destacan años de importantes devaluaciones. Para el período más reciente es posible mencionar una incidencia combinada, con un tipo de cambio subvaluado a comienzos del período, pero que tiende a sobrevaluarse vigorosamente a partir del año 2008 (Kennedy, 2015), y un fuerte incremento de precios en la segunda parte del período, que declina en los últimos años.

El efecto central de la sobrevaluación sobre los ingresos estatales se pone de relieve en los movimientos que presenta el alza de precios de las mercancías agrarias (representado en el "índice de precios de granos") y el peso diferencial en la recaudación y en el PBIpm. Como se ve en la Figura 3, tanto para 2008 como para 2011 y 2012, se evidencia que los niveles de los precios de las mercancías exportadas, en moneda extranjera, eran prácticamente idénticos, sin embargo, en el mismo nivel, el peso de los derechos de exportación en la recaudación total baja abruptamente sin haber un cambio en las cantidades demandadas $^{18}$. Como vemos, esta baja abrupta está montada, y determinada, por la marcada tendencia a la sobrevaluación cambiaria que presenta el tipo de cambio real, estrangulando los ingresos estatales ${ }^{19}$.

17 Es necesario realizar algunas salvedades sobre tales series. En primer lugar, en relación a la serie de tipo de cambio real, se presenta como indicador de períodos en los cuales la moneda tiende a sobrevaluarse o subvaluarse, pero sin entrar aquí en la discusión respecto del momento en el cual la moneda se encontraba en su nivel de paridad. En segundo lugar, la serie de índices de precios de granos no considera la participación de los distintos granos en las exportaciones nacionales a través de los años, las cuales son cambiantes, ya que la soja comienza a cobrar relevancia hacia mediados de los años ochenta, mientras que previamente el maíz y el trigo (también la carne vacuna, aunque aquí no se encuentra representada) poseían mayor peso. Por lo tanto, también es un indicador general de evolución, ya que si bien en general la tendencia de todas las mercancías es similar, presentan diferentes intensidades y ciclos particulares. Por último, cabe aclarar que presentar la evolución de precios deja de lado el otro componente que hace a la masa de renta que fluye al país, es decir, las cantidades comercializadas, de ahí que no haya que asociar de manera directa a la evolución de los precios con la participación de los impuestos a las exportaciones en el PBI o en la recaudación, cuestión además mediada por el tipo de cambio.

18 Como se desprende de la evolución de los índices de cantidades de las exportaciones de productos primarios con base en las estimaciones de INDEC publicadas por el Ministerio de Hacienda.

19 Cabe aclarar que las participaciones diferenciadas no se explicarían tampoco por el crecimiento de la producción interna con volúmenes de exportaciones constantes, ya que el PBIpm a precios contantes subió desde 2008 a 2012 solo un $8,7 \%$, contrastando contra una apreciación del tipo de cambio del $28,7 \%$ en el mismo periodo. 


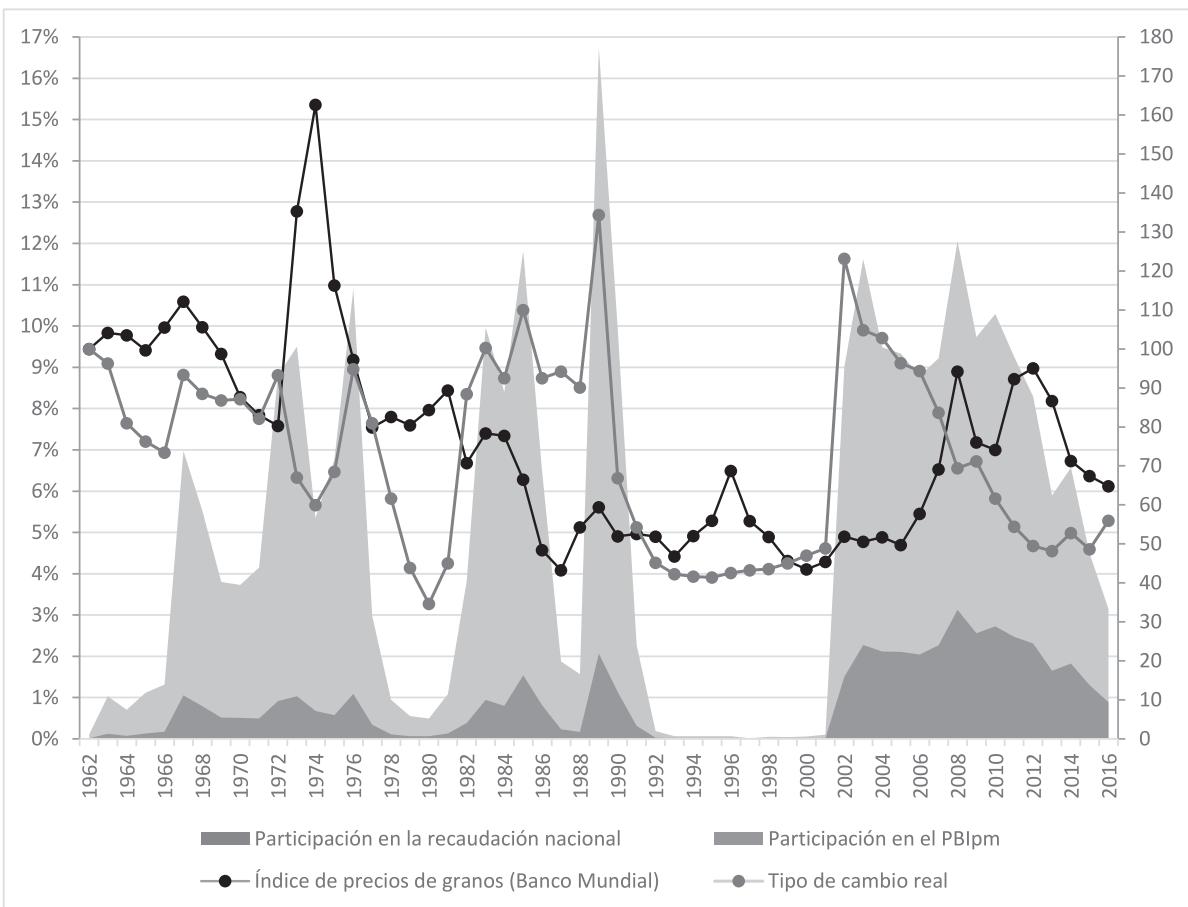

Figura 3. Participación de los derechos de exportación en el PBIpm a precios corrientes y en la recaudación nacional (eje izquierdo). Índice de precios reales de granos (Banco Mundial, s.f.) e índice del tipo de cambio real (evolución 1962=100, eje derecho). 1962-2016.

Fuente: elaboración propia con base en Anuarios AFIP, Banco Mundial, BLS, CIFRACTA (IPC-9 Provincias), INDEC, Iñigo (2007, actualizado a 2016), Kennedy, Pacífico y Sánchez (2018) y Ministerio de Hacienda (Información Económica al Día).

Los derechos de exportación en Argentina durante la postconvertibilidad. La desagregación sectorial para el período 2003-2014

Concentrémonos, ahora sí, en lo ocurrido entre los años 2003-2014 con los impuestos a las exportaciones. En un primer momento, la composición de la recaudación del impuesto se presenta según ramas de actividad (tal como se clasifican usualmente las actividades en el marco de las Cuentas Nacionales), esto es, sin diferenciar la actividad en la que se origina la riqueza social que posibilita el cobro del impuesto, sino aquella a la que fluye y sobre la que recae el cobro efectivo por parte del Estado, las cuales aquí presentamos agrupadas en el nivel de grandes sectores (Figura 4). 


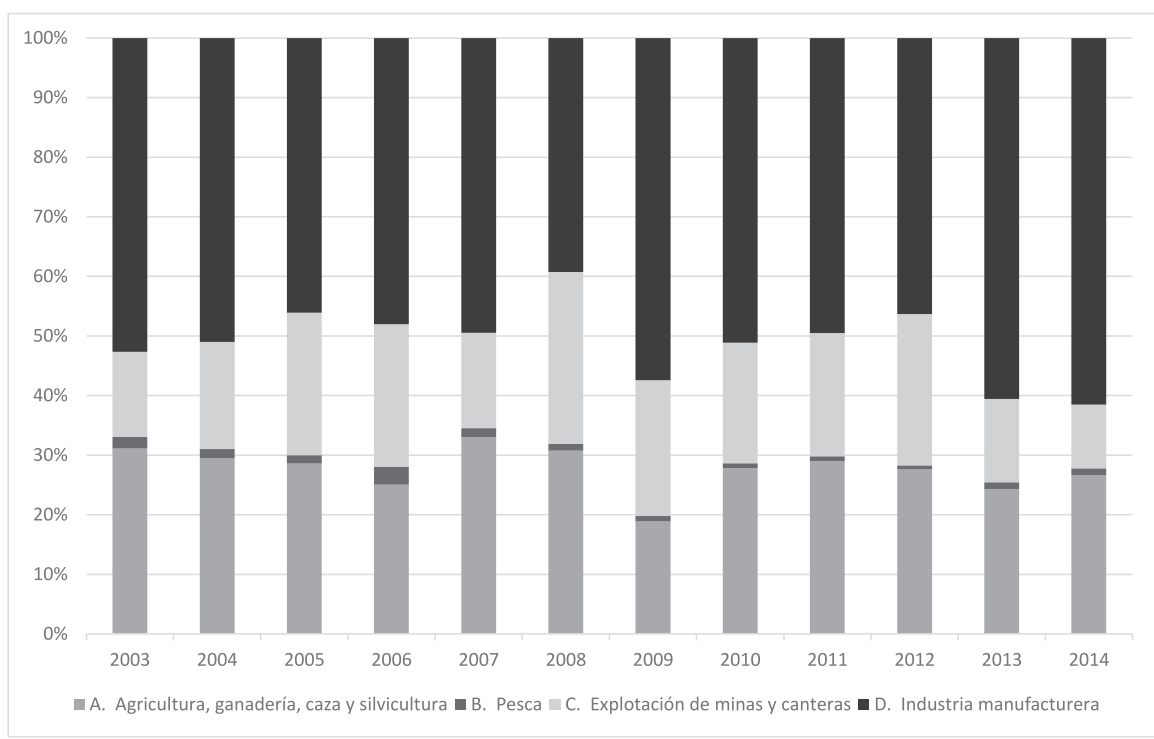

Figura 4. Composición de los derechos de exportación según grandes ramas de actividad. Argentina. 2003-2014.

Nota: la estimación surge del siguiente agrupamiento de las secciones de la NCM: A (secciones I y II, sin considerar productos pesqueros); B (productos pesqueros comprendidos en la sección I); $\mathrm{C}$ (sección $\mathrm{V}$, sin considerar energía eléctrica); D (secciones III y IV y VI a XXI, más energía eléctrica).

Fuente: elaboración propia con base en Aduana, AFIP, INDEC y MECON.

Con fundamento en lo anterior, como se muestra en la Figura 5, es posible realizar una reclasificación de las actividades considerando los derechos de exportación en función de las ramas en las que efectivamente se origina la fuente de riqueza social que aporta a la recaudación del impuesto y no sobre aquellas en las que realmente se realiza el pago al Estado nacional ${ }^{20}$. Como allí se observa, las actividades clasificadas dentro de la industria manufacturera pasan a representar una parte minoritaria en la recaudación del impuesto, aunque ello no da cuenta de lo verdaderamente apropiado sobre cada rama, para lo cual es necesario plantear un último momento de análisis.

20 Corresponde aclarar que aquellas porciones de plusvalía plausibles de ser liberadas sobre las fases de procesamiento de las materias primas identificadas anteriormente o porciones de plusvalía normal apropiadas a partir del cobro del impuesto y que podrían hacer a la recaudación del mismo, no son tenidas en cuenta en esta reclasificación. Es decir, en caso de existir alguno de tales fenómenos, se estarían considerando aquí como un flujo de plusvalía bajo la forma de renta de la tierra. 


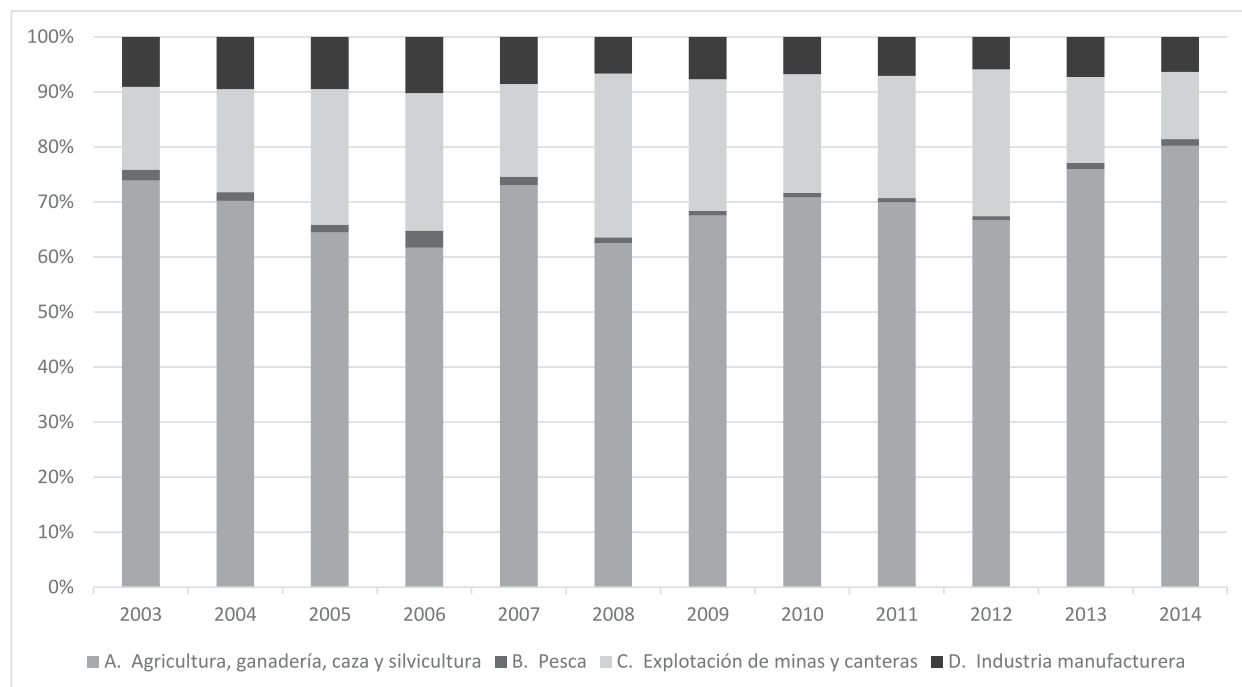

Figura 5. Composición de los derechos de exportación según grandes ramas de actividad. (reclasificación propia). Argentina. 2003-2014.

Nota: la reclasificación propuesta surge del siguiente reagrupamiento de las posiciones arancelarias de la NCM, a partir del agrupamiento mostrado en la Figura 4: A (secciones I y II, sin considerar productos pesqueros; secciones III y IV, sin considerar productos pesqueros; productos frutícolas,

forestales, ganaderos y oleaginosos comprendidos en la sección VI; productos forestales comprendidos en la sección VII; secciones VIII y IX); B (productos pesqueros comprendidos dentro de la sección I; productos pesqueros comprendidos en las secciones III y IV); C (sección $\mathrm{V}$, sin considerar energía eléctrica; productos de origen minero de las secciones VI, XIV y XV);

D (surge de restar al agrupamiento anterior las posiciones adicionadas a las letras A, B y C).

Fuente: elaboración propia con base en Aduana, AFIP, INDEC y MECON.

Como puede verse en la Figura 6, si se sustraen los reintegros a las exportaciones es posible observar la riqueza social efectivamente apropiada sobre cada rama de actividad y, por ende, las actividades a partir de las cuales fluyen en términos efectivos porciones de riqueza social con fuente en la renta de la tierra a manos del Estado nacional.

En este sentido, en el caso de las actividades clasificadas dentro de la industria manufacturera, los derechos de expor- tación pagados quedan prácticamente compensados (en algunos años resultan más que compensados) por el efecto de los reintegros a las exportaciones, mientras que la totalidad de la recaudación se concentra en porciones de riqueza social que originalmente previenen de las actividades agropecuarias, pesqueras y mineras. Entre estas últimas, tomando el promedio del período analizado, las actividades agropecuarias representan el $74,5 \%$ del total, mientras que las de origen minero y pesquero representan 
el 23,8 \% y $1,3 \%$, respectivamente. La menor exportación de hidrocarburos, que resulta notoria en los últimos años del período analizado, es uno de los factores que explica el crecimiento de la participación de la actividad agropecuaria en el total, la cual se ubicó alrededor del $85 \%$ en 2014. No obstante, tal incremento no fue lineal a lo largo del período ni tampoco similar para las distintas actividades que conforman las ramas. Sobre este punto, vale mencionar algunos aspectos relevantes.

En primer lugar, en términos de actividades productivas, se destacan las vinculadas al complejo oleaginoso (58,1 \% de la recaudación del impuesto, considerando el promedio del período analizado), petrolero (21,4\%), cerealero $(12,5 \%)$, minería metalífera $(2,6 \%)$, ganadero $(2,3 \%)$ y pesquero $(1,3 \%)$. Para el resto de las producciones, la participación es minoritaria y va desde el $0,3 \%$ para el complejo farmacéutico hasta el $-0,8 \%$ para el automotor. En cuanto a la dinámica de la participación en la recaudación, estas actividades presentan marcadas diferencias en función de los niveles de producción exportada (en muchos casos mediados por la intervención del Estado a lo largo del período analizado), los precios internacionales y las alícuotas del propio impuesto. Por ejemplo, la actividad petrolera representaba hacia 2003 el $16,5 \%$ del total, ascendiendo al 30,8\% en 2008 (luego de una brusca caída en 2007), disminuyendo en los años siguientes (21\% en 2010), repuntando en $2012(25,6 \%)$ y volviendo a caer en 2014 hasta el 11,3\%; mientras que la principal contrapartida de ello se explica por lo ocurrido con el complejo oleaginoso con una dinámica inversa a la anterior: participación de $63,4 \%$ en 2003 que disminuye hasta el $47 \%$ en 2008 (luego de un fuerte incremento en 2007), incrementándose fuertemente en los años siguientes (63,6 \% en 2010), con caída en $2012(51,6 \%)$ y un nuevo incremento hasta 2014 (68,1\%).

En segundo lugar, si bien las actividades mencionadas son claramente las relevantes en términos de participación en la recaudación del impuesto, ello no quita que para algunos casos particulares la importancia del impuesto neto sobre las exportaciones sea similar o mayor que en el caso de aquellas. Así, mientras que para las producciones anteriormente mencionadas la alícuota implícita se ubica (en el promedio del período analizado) alrededor del 24,8 \% para el complejo oleaginoso, 22,4\% para el petrolero, $15,6 \%$ para el cerealero, $6,8 \%$ para la minería metalífera, $6,3 \%$ para el pesquero y $4,3 \%$ para el ganadero; también es posible mencionar otras actividades como las del complejo apícola (7,5\%) y tabacalero (5,6 \%).

Por último cabe destacar el alto grado de concentración de los productos sobre los que recae en mayor medida el impuesto (considerado en términos 
netos), ya que en cuatro productos 21 (considerados a 8 dígitos de la NCM) se concentra aproximadamente el $64 \% \mathrm{del}$ total de la recaudación del período (en pesos de poder adquisitivo constante), en seis productos22, aproximadamente el $74 \%$, y en una veintena de productos 23 , el $90 \%$.

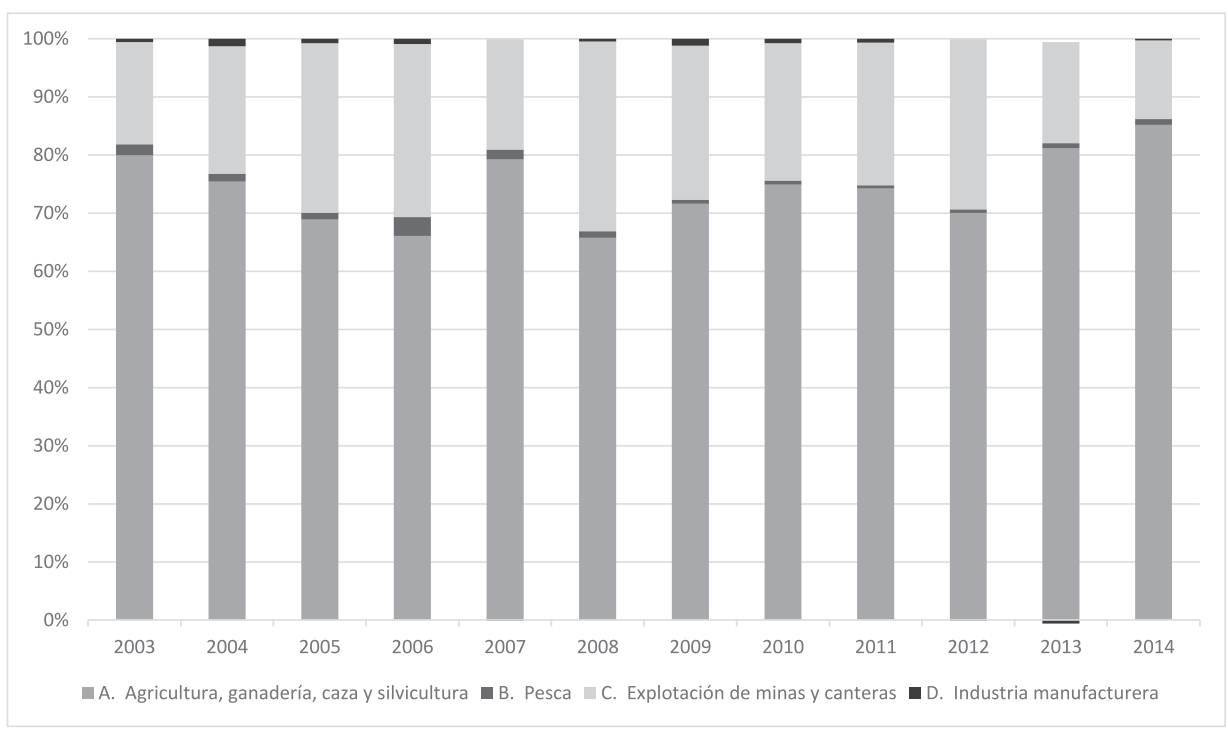

Figura 6. Composición de los derechos de exportación netos de reintegros a las exportaciones, según grandes ramas de actividad (reclasificación propia). Argentina. 2003-2014.

Nota: la estimación surge de restar los reintegros a las exportaciones a las posiciones arancelarias correspondientes a cada rama de acuerdo a la clasificación mostrada en la Figura 5.

Fuente: elaboración propia con base en Aduana, AFIP, INDEC y MECON.

\section{CONCLUSIONES}

El proceso de cuantificar la renta de la tierra que fluye hacia un ámbito nacional y sus cursos de apropiación resulta arduo, metodológicamente hablando $\mathrm{y}$, por supuesto, como todo dato, también discutible. Ello se debe a que el fenómeno en cuestión se diluye en un gran número de mediaciones, entre las cuales los impuestos a las exportaciones se

21 Harina y "pellets" de la extracción del aceite de soja (25,7\%); porotos de soja (excluidos para siembra) (14 \%); aceite de soja en bruto (incluso desgomado) (12,9\%); aceites crudos de petróleo $(11,3 \%)$.

22 A los cuatro anteriores se suman: maíz en grano (5,2 \%); trigo y morcajo (excluidos trigo duro y para siembra) $(5,1 \%)$.

23 A los seis anteriores se suman: aceite de girasol en bruto (2\%); naftas para petroquímica (1,7 \%); minerales de cobre y sus concentrados (excluido sulfuros) (1,6\%); propano licuado (excluido crudo) $(1,6 \%)$; gas natural en estado gaseoso (1,4\%); butanos licuados (1,4\%); naftas (excluidas para petroquímica) $(1,1 \%)$; carne bovina deshuesada (fresca o refrigerada) $(0,9 \%)$; gasolinas excluidas de aviación $(0,8 \%)$; fuel oil $(0,7 \%)$; gas licuado de petróleo (GLP) $(0,6 \%)$; oro para uso no monetario (formas en bruto de aleación dorada o bullón dorado) $(0,6 \%)$; carne bovina deshuesada (congelada) $(0,6 \%$ ); biodisel y sus mezclas (sin aceites de petróleo o de mineral bituminoso o con un contenido <= al $70 \%$ en peso de estos aceites) $(0,6 \%)$. 
conforman como uno de los pilares de dicha apropiación. En este trabajo, nuestra intención ha sido tratar de avanzar en esta cuantificación específica, aportando información detallada, con una clasificación de la información no disponible hasta el momento, no solo para las mercancías agrarias, sino también para aquellas de la actividad petrolera, minera o pesquera.

A su vez, si bien no analizamos aquí la unidad del proceso de acumulación de capital nacional, sino una faceta de su movimiento concreto, consideramos relevante dar cuenta del papel central que ocupa en el mismo el volumen de renta de la tierra que ingresa anualmente al país. Para contribuir en ese sentido, pretendimos poner de manifiesto el origen de la masa de riqueza social apropiada a través del impuesto a las exportaciones y por qué esta no podría tener otra fuente que no sea una fuente extraordinaria de valorización (al menos de manera sostenible), así como las falencias que presentan las estimaciones oficiales de las Cuentas Nacionales para dar cuenta de ello.

\section{AGRADECIMIENTOS}

El presente trabajo se enmarca en las actividades del Proyecto UBACyT 20020150200133BA, Categoría Modalidad II, Programación 2016, período 2016-2017, titulado Acumulación de capital y condiciones de reproducción de la fuerza de trabajo: especificidades de la economía argentina desde mediados de los años setenta, dirigido por Damián Kennedy. A su vez, agradecemos los comentarios realizados a versiones anteriores por Damián Kennedy, así como las observaciones de los evaluadores anónimos y el equipo editorial de la revista Apuntes del Cenes, los cuales resultaron de suma utilidad en el proceso de elaboración del trabajo. 


\section{REFERENCIAS}

Aduana Argentina. (s.f.). Nomenclatura Común del Mercosur (NCM). Buenos Aires: Aduana.

AFIP. (s.f.). Anuarios estadísticos: recaudación total del Estado nacional. Recaudación de derechos de exportación. Buenos Aires: AFIP.

Alvater, E. (1976). Estado y capitalismo. Notas sobre algunos problemas de intervención estatal. Cuadernos Políticos, 9, 9-30.

Arceo, E. (2003). Argentina en la periferia prospera. Renta internacional, dominación oligárquica y modo de acumulación. Bernal, Buenos Aires: Universidad Nacional de Quilmes.

Banco Mundial. (s.f.). Precios internacionales de granos. s.1.: BM.

Cazón, F., Kennedy, D. \& Lastra, F. (2016). Las condiciones de reproducción de la fuerza de trabajo como forma de la especificidad de la acumulación de capital en Argentina: evidencias concretas desde mediados de los 70. Trabajo y Sociedad, (27), 305-327.

Centro de Investigación y Formación de la República Argentina -CIFRA-CTA(s.f.). IPC-9 Provincias. Buenos Aires: CIFRA-CTA.

Diamand, M. (1972). La estructura productiva desequilibrada argentina y el tipo de cambio. Desarrollo Económico, 45, 25-47.

Dileo, E., Graña, J. M., Kennedy, D. \& Sánchez, M. A. (2017). El rol de la deuda pública externa en la acumulación de capital en Argentina: aportes preliminares al debate a partir de su dinámica desde el inicio de la convertibilidad. En 12 Jornadas de Sociología, Facultad de Ciencias Sociales, Universidad de Buenos Aires, 22 al 25 de agosto.

Dirección Nacional de Investigaciones y Análisis Fiscal -DNIAF- (2017). Tributos vigentes en la República Argentina a nivel nacional. Buenos Aires: Subsecretaría de Ingresos Públicos, Secretaría de Hacienda, Ministerio de Hacienda.

Fröbel, F., Heinrichs, J. \& Kreye, O. (1980). La nueva división internacional del trabajo. Paro estructural en los paises industrializados e industrialización de los paises en desarrollo. Madrid: Siglo XXI.

Graña, J. M. (2013). Las condiciones productivas de las empresas como causa de la evolución de las condiciones de empleo: la industria manufacturera en Argen- 
tina desde mediados del siglo pasado. Tesis doctoral, Doctorado en Ciencias Económicas con mención en Economía, Facultad de Ciencias Económicas, Universidad de Buenos Aires.

Grinberg, N. (2013). Capital Accumulation and Ground-Rent in Brazil: 1953-2008. International Review of Applied Economics, 27, 449-471.

Grinberg, N. (2016). Global Commodity Chains and the Production of Surplus-value on a Global Scale: Ringing Back the New International Division of Labour Theory. Journal of World-Systems Research, 22(1), 247-278. https://doi. org/10.5195/JWSR.2016.605

Instituto Nacional de Estadística y Censos -INDEC- (2016). Cuentas Nacionales, metodología de estimación. Base 2004 y serie a precios constantes y corrientes, metodología $n .^{\circ} 21$. Buenos Aires: INDEC.

Iñigo, J. (1998). La acumulación de capital en la Argentina. Buenos Aires: Centro para la Investigación como Crítica Práctica.

Iñigo, J. (2007). La formación económica de la sociedad argentina. Volumen I. Renta agraria, ganancia industrial y deuda externa. 1982-2004. Buenos Aires: Imago Mundi.

Iñigo, J. (2008). La unidad mundial de la acumulación de capital en su forma nacional históricamente dominante en América Latina. Crítica de las teorías del desarrollo, de la dependencia y del imperialismo. En IV Coloquio Internacional de la Sociedad Latinoamericana de Economía Política, Buenos Aires, 22 al 24 de octubre.

Jaccoud, F., Arakaki, A., Monteforte, E., Pacífico, L., Graña, J. M. \& Kennedy, D. (2015). Estructura productiva y reproducción de la fuerza de trabajo: la vigencia de los limitantes estructurales de la economía argentina. Cuadernos de Economía Crítica, 2, 79-112.

Kennedy, D. (2015). Las fuentes de compensación desde la perspectiva de la contabilidad social y su rol en el ciclo económico. Convertibilidad y postconvertibilidad en perspectiva histórica. En J. Lindenboim \& A. Salvia (coord.), Hora de balance: proceso de acumulación, mercado de trabajo y bienestar. Argentina 2002-2014 (pp. 75-107). Buenos Aires: EUDEBA.

Kennedy, D. (2016). Fundamentos económicos y cuentas nacionales: una propuesta de medición de la evolución del valor. Cuadernos de Economía, 35(68), 407-431. 
Kennedy, D., Pacífico, L. \& Sánchez, M. A. (2018). La evolución de la economía argentina a partir de la publicación de la base 2004 de las cuentas nacionales. Reflexiones a partir de la consideración del doble carácter del producto social en perspectiva histórica. Cuadernos de Economía Crítica, 8, en prensa.

Marx, K. (2011a). El capital. Crítica de la economía política. Tomo I. Buenos Aires: Siglo XXI.

Marx, K. (2011b). El capital. Crítica de la economía política. Tomo III. Buenos Aires: Siglo XXI.

Ministerio de Hacienda (s.f.). Información económica al día. Buenos Aires: Ministerio de Hacienda.

Müller, W. \& Neusüss, C. (1975). The Illusion of State Socialism and the Contradiction between Wage Labour and Capital. Telos, 25, 13-90.

Piermartini, R. (2004). The Role of Export Taxes in the Field of Primary Commodities. World Trade Organization Discussion Papers, Ginebra. Recuperado de https://www.wto.org/english/res_e/booksp_e/discussion_papers4_e.pdf

Prebisch, R. (1986). El desarrollo económico de la América Latina y algunos de sus principales problemas. Desarrollo Económico, 26(103), 479-502. 


\begin{abstract}
ANEXO 1
Luego de la crisis que marcó el fin de la convertibilidad, período en el cual la relevancia de los impuestos a las exportaciones prácticamente había desaparecido, a comienzos del año 2002, mediante el Decreto 310/2002, se determinaron el nivel y el alcance de los derechos de exportación "aplicable a mercaderías comprendidas en posiciones arancelarias de la Nomenclatura Común del MERCOSUR (N.C.M.)", bajo la explícita necesidad de paliar la "grave situación por la que atraviesan las finanzas públicas". En aquel momento, el impuesto en cuestión se fijó en el 20 \% para el aceite crudo de petróleo y mineral bituminoso y $5 \%$ para ciertas preparaciones y desechos.
\end{abstract}

A partir de ahí, hasta fines de 2015, se inició un complejo proceso de modificaciones del esquema del impuesto, que tendió hacia la ampliación de su alcance y el incremento en los niveles de la alícuota para las mercancías comprendidas en las posiciones arancelarias de la NCM. Ello, a su vez, hizo que la riqueza social apropiada por esta vía pasara a representar una proporción relevante de los ingresos fiscales del Estado nacional (aunque desvaneciéndose paulatinamente hacia fines del período analizado). Entre las normas más relevantes que conformaron tal proceso[24] se encuentran la inmediatamente posterior Resolución 11/2002 del Ministerio de Economía e Infraestructura (modificada por la Resolución 35/2002 del Ministerio de Economía), a través de la cual se extienden de manera considerable las posiciones arancelarias alcanzadas por el gravamen a prácticamente la totalidad de la NCM (excepto los hidrocarburos y sus derivados comprendidos dentro de los alcances del Decreto 1589/1989), con una alícuota del $20 \%$ para mercancías agrarias específicas y sus derivados (principalmente soja, girasol, trigo y maíz) y $5 \%$ para el resto, nuevamente bajo el argumento del "deterioro en los ingresos fiscales, que a su vez se encuentra acompañado por una creciente demanda de asistencia para los sectores más desprotegidos" y la necesidad de atenuar "el efecto de las modificaciones cambiarias sobre los precios internos, especialmente en lo relativo a productos esenciales de la canasta familiar". Aún en el 2002, mediante el Decreto 690/2002, además de modificarse los derechos de exportación de las normas mencionadas anteriormente, se fijan los reintegros a las exportaciones para un conjunto de posiciones arancelarias. Estos, como puede verse en el cuerpo del texto, también tendrían un papel relevante en el período bajo análisis, particularmente para las mercancías de índole industrial.

Posteriormente, ante el fuerte incremento de precios internacionales, mediante la Resolución 10/2007 del Ministerio de Economía y Producción se fijó un derecho de exportación adicional del $4 \%$ para ciertas mercancías de origen agrícola y sus derivadas (ligadas a la cadena de la soja) y por medio de la bien conocida Resolu- 
ción 125/2008 (y su modificatoria -Resolución 141/2008-, derogatoria -Resolución 64/2008- y complementarias -Resoluciones 284/2008 y 285/2008-, todas del Ministerio de Economía y Producción) se modificaron los derechos de exportación sobre las principales mercancías agrarias exportadas a partir de una fórmula que establece un esquema móvil para la determinación del nivel del impuesto en función del movimiento de los precios internacionales (elevándolos para la soja y el girasol y sus derivados y reduciéndolos para el maíz y el trigo). Dicho esquema fue modificado por la Resolución 64/2008 del Ministerio de Economía y Producción (estableciendo alícuotas para distintos niveles del precio internacional, llegando al 52,7 \% cuando el precio FOB alcanzaba los 750 dólares en el caso de la soja y 900 dólares en el caso del girasol), y complementado por una compensación para pequeños productores de soja o girasol de la cosecha 2007/2008 (Resolución 284/2008 del Ministerio de Economía y Producción) y para el transporte de granos oleaginosos (soja y girasol) producidos en las provincias extra pampeanas (Resolución 285/2008 del Ministerio de Economía y Producción). No obstante, como es sabido, el conflicto político que desató la implementación de la "Resolución 125" tuvo una resolución "no positiva" y su vigencia (así como la de su modificatoria, derogatoria y complementarias) se limitó mediante la Resolución 180/2008 del Ministerio de Economía y Producción, restituyendo los niveles de derechos de exportación previos (Resoluciones 368/2007 y 369/2007 del Ministerio de Economía y Producción).

Dicho conflicto marcó, en gran medida, el límite para la extensión del impuesto. De hecho, desde entonces, y hasta el 2015, los derechos de exportación para las principales mercancías agrarias exportadas se mantuvieron constantes, siendo del $35 \%$ para los porotos de soja y del $32 \%$ para sus derivados y subproductos, $15 \%$ para el maíz en grano, $23 \%$ para el trigo y $30 \%$ para el aceite de girasol. Mientras que prácticamente para la totalidad de las mercancías industriales dicha alícuota se ubicó en el $5 \%$, aunque con reintegros que generalmente variaban entre $2.5 \%$ y $6 \%$.

Párrafo aparte merece la trayectoria de los impuestos a las exportaciones de hidrocarburos y sus derivados (aquí mencionada breve y parcialmente a partir de las principales normas identificadas), siendo el conjunto de mercancías que sufrió el mayor número de modificaciones en cuanto al alcance y nivel de los derechos de exportación entre 2002 y 2015. En este sentido, luego del mencionado Decreto 310/2002, el Decreto 809/2002 amplió las posiciones arancelarias sujetas al impuesto. Más adelante, a partir del incremento de los precios internacionales, por medio de la Resolución 335/2004 del Ministerio de Economía y Producción se elevó la alícuota al 20 \% para un conjunto de productos; en la Resolución 336/2004 del Ministerio de Economía y Producción se incrementó al $5 \%$ el impuesto para las naftas (para las 
que se había fijado el $0 \%$ en la Resolución 135/2002 del Ministerio de Economía); en la Resolución 337/2004 del Ministerio de Economía y Producción se incrementó la alícuota al $25 \%$ para las exportaciones de aceite crudo de petróleo y de mineral bituminoso; mientras que el Decreto 645/2004 fijó el derecho de exportación al gas natural licuado, al gas natural en estado gaseoso, al butano en estado gaseoso y a otros gases en el 20 \%. Luego, la Resolución 532/2004 (y su complementaria 537/2004) del Ministerio de Economía y Producción mantuvieron el derecho de exportación del $25 \%$ para el aceite crudo de petróleo y mineral bituminoso, pero establecieron la aplicación de alícuotas adicionales (pudiendo llegar hasta el $45 \%$ ) en aquellos casos en los que el precio internacional sea superior a un determinado monto en dólares, lo cual introdujo como aspecto novedoso en el período aquí analizado la implementación de alícuotas móviles para el impuesto. En el mismo sentido, la Resolución 394/2007 del Ministerio de Economía y Producción deroga la resolución previa y modifica los derechos de exportación a los hidrocarburos aplicando una alícuota del $45 \%$, que resultaría superior si el precio internacional de las mercancías en cuestión superaba un nivel de referencia especificado en cada caso (aunque si el precio fuera inferior a un determinado nivel, los porcentajes por aplicar deberían determinarse a posteriori). Por último, por medio de la Resolución 1077/2014 del Ministerio de Economía y Finanzas Públicas se deroga la Resolución 394/2007, creando un nuevo esquema de derechos de exportación para los hidrocarburos y sus derivados, pero que mantiene las alícuotas móviles.

Finalmente, si bien excede el período aquí analizado, con el cambio de gobierno de fines de 2015 se implementaron diversas medidas que determinaron, en algunos casos, la reducción de los derechos de exportación, mientras que en otros, su total eliminación. Así, mediante el Decreto 133/2015 se elimina el impuesto para la gran mayoría de las mercancías agropecuarias, con la particular excepción de la soja y sus derivados (para las cuales la alícuota se mantuvo entre el $27 \%$ y $30 \%$ y, a partir del Decreto 1343/2016 se prevé que se reduzcan en un 0,5\% mensual desde enero de 2018 hasta diciembre de 2019). Casi simultáneamente, mediante el Decreto 160/2015, se eliminaron los derechos de exportación para aproximadamente la totalidad de las mercancías industriales. A su vez, mediante el Decreto 349/2016 se eliminan los derechos de exportación a los productos de la actividad minera[25]. Por último, el Decreto 1341/2016 incrementa los niveles de los reintegros a la exportación para diversos productos agrarios y agroindustriales. 